\title{
Cost-Effectiveness Assessment of Different Glucosamines in Patients with Knee Osteoarthritis: A Simulation Model Adapted to Germany
}

\author{
Olivier Bruyère, ${ }^{1, *}$ Johann Detilleux ${ }^{2}$ and Jean-Yves Reginster ${ }^{1,3}$
}

${ }^{I}$ Division of Public Health, Epidemiology and Health, Economics, WHO Collaborating Centre for Public Health, Aspects of Musculo-Skeletal Health and Ageing, University of Liège, Belgium; ${ }^{2}$ Department of Veterinary Management of Animal Resources, University of Liège, Belgium; ${ }^{3}$ Chair for Biomarkers of Chronic Diseases, Department of Biochemistry, College of Science, King Saud University, Riyadh, KSA

\begin{abstract}
Background: The use of symptomatic slow-acting drugs for osteoarthritis (OA) (e.g., glucosamine, chondroitin) is largely debated in the scientific literature. Indeed, multiple formulations of these agents are available, both as pharmaceutical-grade products and as nutritional supplements, but while all preparations may claim to deliver a therapeutic effect, not all are supported by clinical evidence. Moreover, few data are available regarding the cost-effectiveness of all these formulations. Usually, access to individual patient data is required to perform economic evaluations of treatments, but it can be challenging to obtain. We previously developed a model to simulate individual health utility scores from aggregated data obtained from published OA trials.
\end{abstract}

Received: October 07, 2020 Revised: January 20, 2021 Accepted: February 11, 2021

DOI:

$10.2174 / 1874609814666210415092845$
Objective: In the present study, using our new simulation model, we investigated the costeffectiveness of different glucosamines used in Germany.

Methods: We used our validated model to simulate the utility scores of 10 published trials that used different glucosamine preparations. Using the simulated utility scores, the quality-adjusted life years (QALYs) were calculated using the area-under-the-curve method. We used the 2018 public costs of glucosamine products available in Germany to calculate the Incremental Cost/Effectiveness Ratio (ICER). We performed analyses for pharmaceutical-grade Crystalline Glucosamine Sulfate (pCGS) and other formulations of glucosamine (OFG). A cost-effectiveness cut-off of 30,000 €/QALY was considered.

Results: Of 10 studies in which utility was simulated, four used pCGS, and six used OFG. The ICER analyses showed that pCGS was cost-effective compared to a placebo, with an ICER of 4489 $€ /$ QALY at month 3, $4112 € / \mathrm{QALY}$ at month 6 , and $9983 € / \mathrm{QALY}$ at year 3 . The use of OFG was not cost-effective at any of the time points considered.

Conclusion: Using our previously published model to simulate the individual health utility scores of patients, we showed that, in the German context, the use of pCGS could be considered costeffective, while the use of OFG could not. These results highlight the importance of the formulation of glucosamine.

Keywords: Cost-effectiveness, Glucosamine, Osteoarthritis, QALY, Model, Utility score.

\section{INTRODUCTION}

Ageing impairs most physical capacities, and the causes of accelerated degeneration with age are mainly sedentary and unhealthy lifestyles [1]. These variables are also risk factors for osteoarthritis (OA). OA is the most frequent form of arthritis and a leading cause of pain and disability that can

*Address correspondence to this author at the Division of Public Health, Epidemiology and Health, Economics, WHO Collaborating Centre for Public Health, Aspects of Musculo-Skeletal Health and Ageing, University of Liège, Belgium; Tel: +32 436625 81; E-mail: olivier.bruyere@uliege.be negatively impact the health-related quality of life (HRQoL) of patients $[2,3]$. The pathogenesis of $\mathrm{OA}$ is complex, with mechanical, genetic, metabolic, and inflammatory pathways involved. There is some evidence that there are different OA phenotypes that reflect different mechanisms of the disease [4]. Risk factors can be divided into person-level factors, such as sociodemographic characteristics (e.g., age, sex, obesity, race/ethnicity), genetic predispositions, and diet, and joint-level factors, including injury, malalignment, and abnormal loading of the joints [5]. However, it should be acknowledged that very few pharmacological treatments 
have been shown to modulate their effects according to the specificity of OA phenotypes.

As a result of the disability caused by OA, there is a potential cost to the global economy. Indeed, healthcare resources and costs associated with managing OA can be substantial. There have been many studies illustrating the extent of economic burden due to knee OA. In a systematic review of 39 studies that investigated the socioeconomic cost of $\mathrm{OA}$, the authors found that the annual incremental healthcare costs of generalized OA ranged from $€ 705$ to $€ 19,715$, and the non-healthcare-related costs ranged from $€ 432$ to $€ 11,956$ [6]. The authors concluded that the social cost of OA could be between $0.25 \%$ and $0.50 \%$ of a country's GDP. Another systematic literature search on the economic consequences of hip and knee OA included 32 articles and showed that the annual total costs per patient ranged from 0.7 to 12 $\mathrm{k} €$, the direct costs per patient ranged from 0.5 to $10.9 \mathrm{k} €$ and the indirect costs per patient ranged from 0.2 to $12.3 \mathrm{k} €$ [7]. The authors noted that the weighted average annual costs per patient living with knee and hip OA were 11.1, 9.5, and $4.4 \mathrm{k} €$ for total, direct and indirect costs, respectively.

Numerous pharmacologic and nonpharmacologic treatment options are available to manage individuals with knee OA. A number of recent guidelines have been developed to help the treatment and management of knee OA [8-10]. In the clinical practice guidelines for knee OA treatment released by the European Society for Clinical and Economic Aspects of Osteoporosis, Osteoarthritis and Musculoskeletal Diseases (ESCEO), the recommended approach, in addition to nonpharmacologic treatment, is to initiate background therapy with chronic symptomatic slow-acting drugs for OA (SYSADOAs). However, there are many different agents in the class of SYSADOAs, including glucosamine, chondroitin, diacerein, and avocado soybean unsaponifiables, which are supported by heterogeneous clinical data. Moreover, multiple formulations of these agents are available, both as pharmaceutical-grade products and nutritional supplements. However, while all preparations may claim to have a therapeutic effect, not all are supported by clinical evidence [11]. Thus, when focusing on glucosamine products, the ESCEO working group affords a strong recommendation to the use of pharmaceutical-grade crystalline glucosamine sulfate (pCGS) as long-term background therapy for the management of knee OA and discourages the use of other formulations of glucosamine (OFG) [10]. It is anticipated that the future will bring disease-modifying treatments, but it is likely that these will be expensive and ineffective in some patients. It is, therefore vital that the costs and the impact on the HRQoL of the treatment are investigated so that the costeffectiveness of treatments can be examined and compared [12]. It is indeed important that in a world with limited resources and health care budgets, scarce resources are allocated efficiently.

Economics evaluation is one of the tools that could help allocate resources more efficiently [13]. The most widely used type of health economic analysis is cost-utility analysis since it allows comparisons of different diseases. In these analyses, the outcome of interest is the quality-adjusted lifeyear (QALY), a generic measure of disease burden, including both the quality and the quantity of life lived. It is indeed a product of life expectancy and HRQoL expressed in utility (i.e., a measure of the value that an individual gives to a particular health state). Unfortunately, very few clinical trials have directly assessed the utility of QALYs in OA. However, we previously developed a model to simulate individual health utility scores from aggregated data obtained in published trials [14]. In the present study, we investigated, using our new simulation model, the cost-effectiveness of the use of different glucosamines in a German context.

\section{METHODS}

\subsection{Clinical Trials Included}

We used our published model to simulate the utility scores of published trials [14]. The basic principle of our model was to estimate utility and QALYs with data from clinical trials of glucosamine. We took into account all clinical trials used in the latest independent meta-analysis of glucosamine published in 2014 [15]. However, since our new model was based on the transformation of the WOMAC score into a utility score using a validated formula, we only included clinical trials that used the WOMAC score as an outcome measure (see below). Consequently, as explained below, a total of 10 studies were included (Table 1) [16-25]. This study was carried out in accordance with the Helsinki Declaration Principles.

\subsection{Model Description}

Our model was based on 2 main characteristics. First, we used a validated linear regression model to estimate utility scores based on the age of the patient, the number of years since he/she was diagnosed with OA and the three different WOMAC subscale scores [26]. In fact, Grootendorst developed and estimated a prediction model using linear regression to map the WOMAC along with basic demographic and OA disease severity data into utility scores. The utility score $=0.5274776+0.0079767 \times$ Pain $+.0065111 \times$ Stiffness $0.0059571 \times$ Function $+0.0019928 \times$ Pain $\times$ Stiffness + $0.0010734 \times$ Pain $\times$ Function $+0.0001018 \times$ Stiffness $\times$ Function $-0.0030813 \times$ Pain $^{2}-0.0016583 \times$ Stiffness $^{2}-$ $0.000243 \times$ Function $^{2}+0.0113565 \times$ Age in years $0.0000961 \times$ Age in years $^{2}-0.0172294 \times$ Female $0.0057865 \times$ Years since onset of OA in the study knee + $0.0001609 \times$ Years since onset of OA in the study $\mathrm{knee}^{2}$. The root mean square error of the model was $0.1628(95 \% \mathrm{Cl}$ 0.1457 to 0.1779 ), the mean absolute error was 0.2065 (0.1846 to 0.2273 ), and the mean error was -0.0006 (0.0422 to 0.0397 ). Second, means and SD were extracted from published articles after correction for the scales (to be on the scale for WOMAC indexes as the one used in the equation of Grootendorst), and we replaced missing data in the summary statistics of published studies with data from the study used to develop and validate the procedure [14]. We then simulated a total of 40,000 patients in each study (20,000 glucosamine and 20,000 placebo) using the SIMNORMAL procedure of SAS that performs conditional and unconditional simulations for a set of correlated normal or Gaussian random variables. 
Table 1. General and demographic characteristics of the included trials.

\begin{tabular}{|c|c|c|c|c|c|c|c|}
\hline First author & $\begin{array}{c}\text { Year of Publica- } \\
\text { tion }\end{array}$ & $\begin{array}{l}\text { Study Duration } \\
\text { (weeks) }\end{array}$ & $\begin{array}{l}\text { Type of Glu- } \\
\text { cosamine }\end{array}$ & $\begin{array}{l}\text { Population In- } \\
\text { cluded (N) }\end{array}$ & Women $(\mathbf{N})$ & $\begin{array}{c}\text { Mean Age } \\
\text { (years) }\end{array}$ & $\begin{array}{c}\text { Mean OA Symp- } \\
\text { toms Duration } \\
\text { (years) }\end{array}$ \\
\hline Chopra et al. & 2011 & 16 & OGF & 70 & 54 & 54 & 5 \\
\hline Cibere et al. & 2004 & 24 & OGF & 137 & 77 & 64 & 3 \\
\hline Clegg et al. & 2006 & 24 & OGF & 630 & 399 & 58 & 10 \\
\hline Frestedt et al. & 2008 & 12 & OGF & 35 & 21 & 59 & NA \\
\hline Giordano et al. & 2009 & 12 & pCGS & 60 & 42 & 58 & 6.3 \\
\hline Herrero-Beaumont et al. & 2007 & 24 & pCGS & 210 & 185 & 64 & 7.3 \\
\hline Houpt et al. & 199 & 8 & OGF & 101 & 73 & 64 & 8.3 \\
\hline McAlindon et al. & 2004 & 12 & OGF & 205 & 132 & $>44$ & NA \\
\hline Pavelka et al. & 2002 & 156 & pCGS & 202 & 157 & 62 & 10.6 \\
\hline Reginster et al. & 2001 & 156 & pCGS & 212 & 162 & 66 & 7.8 \\
\hline
\end{tabular}

Table legend: OA, osteoarthritis; NA, not available; pCGS, pharmaceutical-grade crystalline glucosamine sulfate; OGF, other formulations of glucosamine.

Table 2. Incremental cost-effectiveness ratio results for studies using pCGS.

\begin{tabular}{|c|c|c|c|}
\hline & At 3 months & At 6 months & At 36 months \\
\hline \hline Mean (SD) QALY change pCGS & $0.0164(0.018)$ & $0.0413(0.038)$ & $0.2701(0,257)$ \\
\hline Mean (SD) QALY change placebo & $-0.0091(0.025)$ & $-0.0128(0.042)$ & $0.1306(0,237)$ \\
\hline Cost pCGS & 119.9 & 239.8 & 1438.6 \\
\hline ICER & $\mathbf{4 7 0 1}$ & $\mathbf{4 4 3 1}$ & $\mathbf{1 0 3 1 2}$ \\
\hline
\end{tabular}

Table legend: SD, standard deviation; QALY, quality-adjusted life years; pCGS, pharmaceutical-grade crystalline glucosamine sulfate; ICER, incremental cost/effectiveness ratio (ICER).

\subsection{Outcome Measures}

We assessed the utility score at baseline and at the end of the trial for 10 glucosamine trials that used the WOMAC index. Among them, 4 used pCGS and 6 used OFG [16-25]. The utility estimates were used to calculate the QALYs using the area under the curve method, which is the weighted average of time spent in the study, and utility value. If more than one study was available for a particular time (e.g., 3 months), we weighted each study according to the number of subjects included in the trial. Regarding the costs, we used the 2018 public costs of glucosamine products available in Germany.

\subsection{Cost-Effectiveness Analysis}

The incremental cost/effectiveness ratio (ICER) was then calculated. It was done by assessing the difference in cost between glucosamine and a placebo (measured in Euros) divided by the difference in their effect (measured in QALY). We separated the analyses for pCGS and OFG. A cost-effectiveness cut-off of $30,000 € /$ QALY was considered.

\section{RESULTS}

Of 10 studies in which utility was simulated, 4 used pCGS. For these 4 studies, when looking at the QALY change after 3 months, we observed an increase of 0.0164 points in the pCGS and a decrease of 0.0091 points in the placebo group. The cost of pCGS for 3 months is $€ 119.9$. The related ICER is then $4701 € / Q A L Y$, suggesting the costeffectiveness of pCGS. Similar results were obtained at 6 and 36 months, with ICERs of 4431 and $10312 € /$ QALY, respectively (Table 2 ).

For the 6 studies that used OFG, the maximum duration of the trial was 6 months, with data available at 2 and 3 months. After 3 months of treatment, the QALY change was 0.0036 in the glucosamine arm and 0.0023 in the placebo arm. With a mean cost of $€ 75.42$ for 3 months, the ICER showed that these OFGs were not cost-effective at 3 months. Similar results were also obtained after 2 months (Table 3 ). Moreover, at 6 months of treatment, from a health economics perspective, the placebo was even better than these formulations.

\section{DISCUSSION}

In our study, using a new model to simulate the individual health utility scores of patients from clinical trials, we have shown that pCGS but not OFG was cost-effective in the management of knee OA in a German context. In a world with increasing pressure on healthcare budgets, it is increasingly important to find the most cost-effective option for 
Table 3. Incremental cost-effectiveness ratio results for studies using other formulations of glucosamine.

\begin{tabular}{|c|c|c|c|}
\hline & At 2 months & At 3 months & At 6 months \\
\hline \hline Mean (SD) QALY change other glucosamines & $0.0025(0.017)$ & $0.0036(0.024)$ & $0.0044(0.053)$ \\
\hline Mean (SD) QALY change placebo & $0.0010(0.015)$ & $0.0023(0.026)$ & $0.0074(0.051)$ \\
\hline Mean cost other glucosamines & 50.28 & 75.42 & 150.84 \\
\hline ICER & $\mathbf{3 3 5 2 0}$ & $\mathbf{5 8 0 1 5}$ & Placebo better \\
\hline
\end{tabular}

Table legend: SD, standard deviation; QALY, quality-adjusted life years; ICER, incremental cost/effectiveness ratio (ICER).

managing OA. It has, of course, to be taken into account when developing a clinical guideline or an algorithm for the management of OA. In the model proposed by ESCEO, education, weight loss (if overweight), and physical exercises are considered the backbone of OA management. Indeed, they have been shown to be effective in the management of OA symptoms, but some data also suggest that they are costeffective [27]. For example, using a validated computer microsimulation, a team recently showed that a physical activity programme had an ICER of $\$ 16,100 /$ QALY in inactive knee OA patients followed over 3 years [28]. In another microsimulation study, a diet and exercise programme in addition to treatment in overweight and obese patients with knee OA showed ICERs of \$34,100/QALY and \$30,000/QALY from the health care sector perspective and the societal perspective, respectively [29]. NSAIDS, recommended by ESCEO and other scientific societies, has also been shown to be cost effective, even with OA subjects with comorbidities [30-33]. Numerous medicoeconomic evaluations are also available showing the cost-effectiveness of hyaluronic acid injection in the management of OA [34-36]. Even total knee arthroplasty and total hip arthroplasty showed evidence of cost-effectiveness when compared to non-operative and nonsurgical procedures, according to a systematic review, including 23 trials [37].

It is acknowledged that compliance and persistence with therapy have some impact on economic evaluation [38, 39]. Since a substantial driver of compliance is safety, it is of primary importance to propose to the patient treatment with a low risk of adverse effects, at least in the early management of the disease. In a recent systematic review and metaanalysis on the safety of SYSADOAs, including 25 trials, it was shown that glucosamine sulfate was not associated with increased odds for any type of adverse event compared with placebo [40]. Of course, the preference of the patient must also be taken into account [41]. In a prospective, internetbased, double-blind survey of 2073 adults with knee OA, it was shown that the treatments most commonly offered to patients were not those perceived as being the most effective [42]. Moreover, patients were willing to pay a premium for treatments that they perceived as being more effective and resulted in longer-lasting pain relief. They also preferred a treatment that can be administered with fewer visits to a physician. All these factors must be taken into account when prescribing OA treatment, as they could impact patient compliance.

In our study, we clearly showed differences in costeffectiveness among the different glucosamine products. In fact, numerous clinical trials have assessed the clinical impact of these products in the management of OA symptoms. Indeed, among glucosamine preparations, only the pCGS formulation has been proven to be efficacious in improving pain and functional impairment, while for all other glucosamine preparations, the evidence repeatedly demonstrates a minimal effect [11]. For example, it has been shown in a meta-analysis that trials using pCGS had a superior outcome on pain in OA compared to other preparations of glucosamine [15]. The major mechanism of action of pCGS could relate to the inhibition of the cytokine intracellular signalling cascade, namely, the activation of the nuclear factor-kappa B pathway [43]. Moreover, in human osteoarthritic chondrocytes, glucosamine sulfate has been shown to inhibit IL-1induced activation [44]. Finally, it is interesting to note that in vivo pCGS consistently reaches the plasma level of approximately $10 \mu \mathrm{M}$ required to inhibit interleukin-1-induced expression of genes involved in the pathophysiology of joint inflammation and tissue destruction [45]. Consequently, the ESCEO guidelines specifically recommend only pCGS to maximize clinical outcomes, while claims of equivalence from other formulations may be considered inappropriate.

We acknowledge some limitations in our study. The first is related to the evaluation of the cost. In the context of reimbursement decisions, guidelines recommend adopting a societal perspective, which is the broadest viewpoint for an economic evaluation. Unfortunately, only the cost of the treatment could be taken into account in our study. The second is the utility estimation from the WOMAC that might not reflect the real accuracy, albeit the equation model was previously validated. The third is that we have been able to assess the utility and then the QALYs of studies that have used the WOMAC score as it was needed for the calculation of the utility score. This means that we did not include many clinical trials that could have changed the results of our study. The last is that we did not have access to the raw data to perform the ICER evaluation; we only had access to data published in the scientific literature. However, we used a simulation model previously developed for a similar purpose.

\section{CONCLUSION}

Using a validated model to simulate the utility scores of 10 published trials, we have shown that, in a German context, that the use of pCGS is cost-effective, while the use of other formulations is not, highlighting the importance of the formulation of glucosamine products. 


\section{LIST OF ABBREVIATIONS}

$\begin{array}{lll}\text { ESCEO } & =\begin{array}{l}\text { European Society for Clinical and Eco- } \\ \text { nomic Aspects of Osteoporosis, Osteo- } \\ \text { arthritis and Musculoskeletal Diseases }\end{array} \\ \text { GDP } & =\quad \begin{array}{l}\text { Gross Domestic Product } \\ \text { HRQoL }\end{array} \\ \text { ICER } & =\text { Health-Related Quality of Life } \\ \text { NSAIDS } & =\begin{array}{l}\text { Non-Steroidal Anti-Inflammatory } \\ \text { Drugs }\end{array} \\ \text { OA } & =\text { Osteoarthritis } \\ \text { OFG } & =\text { Other Formulations of Glucosamine } \\ \text { pCGS } & =\begin{array}{l}\text { pharmaceutical-grade Crystalline Glu- } \\ \text { cosamine Sulfate }\end{array} \\ \text { QALY } & =\begin{array}{l}\text { Quality-Adjusted Life Years } \\ \text { Standard Deviation }\end{array} \\ \text { SYSADOAs } & =\begin{array}{l}\text { SYmptomatic Slow-Acting Drugs for } \\ \text { OsteoArthritis }\end{array} \\ \text { WOMAC } & =\begin{array}{l}\text { Western Ontario and McMaster Uni- } \\ \text { versities Osteoarthritis }\end{array}\end{array}$

ETHICS APPROVAL AND CONSENT TO PARTICIPATE

Not Applicable.

\section{HUMAN AND ANIMAL RIGHTS}

No Animals/Humans were used for studies that are the basis of this research.

\section{CONSENT FOR PUBLICATION}

Not Applicable.

\section{AVAILABILITY OF DATA AND MATERIALS}

The datasets generated during and/or analysed during the current study are available from the corresponding author on reasonable request.

\section{FUNDING}

This study was partly supported by a research grant from MEDA Pharma having grant number 0002019/002/UREG.

\section{CONFLICT OF INTEREST}

OB and JYR have received financial support from MEDA unrelated to the submitted work. JD has no conflicts of interest.

\section{ACKNOWLEDGMENTS}

Olivier Bruyère participated in the design of the study, statistical analyses, and drafting and approval of the manuscript.
Johann Detilleux participated in the design of the study, statistical analyses and approval of the manuscript.

Jean-Yves Reginster participated in the design of the study and approval of the manuscript.

\section{REFERENCES}

[1] Berthelot G, Johnson S, Noirez P, et al. The age-performance relationship in the general population and strategies to delay age related decline in performance. Arch Public Health 2019; 77: 51. http://dx.doi.org/10.1186/s13690-019-0375-8 PMID: 31827790

[2] O'Neill TW, McCabe PS, McBeth J. Update on the epidemiology, risk factors and disease outcomes of osteoarthritis. Best Pract Res Clin Rheumatol 2018; 32(2): 312-26.

http://dx.doi.org/10.1016/j.berh.2018.10.007 PMID: 30527434

[3] Clynes MA, Jameson KA, Edwards MH, Cooper C, Dennison EM. Impact of osteoarthritis on activities of daily living: does joint site matter? Aging Clin Exp Res 2019; 31(8): 1049-56.

http://dx.doi.org/10.1007/s40520-019-01163-0 PMID: 30903599

[4] Vina ER, Kwoh CK. Epidemiology of osteoarthritis: literature update. Curr Opin Rheumatol 2018; 30(2): 160-7.

http://dx.doi.org/10.1097/BOR.0000000000000479 PMID: 29227353

[5] Johnson VL, Hunter DJ. The epidemiology of osteoarthritis. Best Pract Res Clin Rheumatol 2014; 28(1): 5-15. http://dx.doi.org/10.1016/j.berh.2014.01.004 PMID: 24792942

[6] Puig-Junoy J, Ruiz Zamora A. Socio-economic costs of osteoarthritis: a systematic review of cost-of-illness studies. Semin Arthritis Rheum 2015; 44(5): 531-41.

http://dx.doi.org/10.1016/j.semarthrit.2014.10.012 PMID: 25511476

[7] Salmon JH, Rat AC, Sellam J, et al. Economic impact of lowerlimb osteoarthritis worldwide: a systematic review of cost-ofillness studies. Osteoarthritis Cartilage 2016; 24(9): 1500-8. http://dx.doi.org/10.1016/j.joca.2016.03.012 PMID: 27034093

[8] Bannuru RR, Osani MC, Vaysbrot EE, et al. OARSI guidelines for the non-surgical management of knee, hip, and polyarticular osteoarthritis. Osteoarthritis Cartilage 2019; 27(11): 1578-89. http://dx.doi.org/10.1016/j.joca.2019.06.011 PMID: 31278997

[9] Kolasinski SL, Neogi T, Hochberg MC, et al. 2019 American College of Rheumatology/Arthritis Foundation Guideline for the Management of Osteoarthritis of the Hand, Hip, and Knee. Arthritis Rheumatol 2020; 72(2): 220-33.

http://dx.doi.org/10.1002/art.41142 PMID: 31908163

[10] Bruyère $\mathrm{O}$, Honvo $\mathrm{G}$, Veronese $\mathrm{N}$, et al. An updated algorithm recommendation for the management of knee osteoarthritis from the European Society for Clinical and Economic Aspects of Osteoporosis, Osteoarthritis and Musculoskeletal Diseases (ESCEO). Semin Arthritis Rheum 2019; 49(3): 337-50.

http://dx.doi.org/10.1016/j.semarthrit.2019.04.008 PMID: 31126594

[11] Bruyère O, Cooper C, Al-Daghri NM, Dennison EM, Rizzoli R, Reginster JY. Inappropriate claims from non-equivalent medications in osteoarthritis: a position paper endorsed by the European Society for Clinical and Economic Aspects of Osteoporosis, Osteoarthritis and Musculoskeletal Diseases (ESCEO). Aging Clin Exp Res 2018; 30(2): 111-7. http://dx.doi.org/10.1007/s40520-017-0861-1 PMID: 29177637

[12] Hiligsmann M, Cooper C, Arden N, et al. Health economics in the field of osteoarthritis: an expert's consensus paper from the European Society for Clinical and Economic Aspects of Osteoporosis and Osteoarthritis (ESCEO). Semin Arthritis Rheum 2013; 43(3): 303-13.

http://dx.doi.org/10.1016/j.semarthrit.2013.07.003

PMID: 23992801

[13] Angelis A, Lange A, Kanavos P. Using health technology assessment to assess the value of new medicines: results of a systematic review and expert consultation across eight European countries. Eur J Health Econ 2018; 19(1): 123-52. http://dx.doi.org/10.1007/s10198-017-0871-0 PMID: 28303438

[14] Bruyère O, Reginster JY, Honvo G, Detilleux J. Cost-effectiveness evaluation of glucosamine for osteoarthritis based on simulation of 
individual patient data obtained from aggregated data in published studies. Aging Clin Exp Res 2019; 31(6): 881-7.

http://dx.doi.org/10.1007/s40520-019-01138-1 PMID: 30746645

[15] Eriksen P, Bartels EM, Altman RD, Bliddal H, Juhl C, Christensen R. Risk of bias and brand explain the observed inconsistency in trials on glucosamine for symptomatic relief of osteoarthritis: a metaanalysis of placebo-controlled trials. Arthritis Care Res (Hoboken) 2014; 66(12): 1844-55.

http://dx.doi.org/10.1002/acr.22376 PMID: 24905534

[16] Reginster JY, Deroisy R, Rovati LC, et al. Long-term effects of glucosamine sulphate on osteoarthritis progression: a randomised, placebo-controlled clinical trial. Lancet 2001; 357(9252): 251-6. http://dx.doi.org/10.1016/S0140-6736(00)03610-2 PMID: 11214126

[17] Pavelká K, Gatterová J, Olejarová M, Machacek S, Giacovelli G, Rovati LC. Glucosamine sulfate use and delay of progression of knee osteoarthritis: a 3-year, randomized, placebo-controlled, double-blind study. Arch Intern Med 2002; 162(18): 2113-23. http://dx.doi.org/10.1001/archinte.162.18.2113 PMID: 12374520

[18] Herrero-Beaumont G, Ivorra JA, Del Carmen Trabado M, et al. Glucosamine sulfate in the treatment of knee osteoarthritis symptoms: a randomized, double-blind, placebo-controlled study using acetaminophen as a side comparator. Arthritis Rheum 2007; 56(2): 555-67. http://dx.doi.org/10.1002/art.22371 PMID: 17265490

[19] Giordano N, Fioravanti A, Papakostas P, Montella A, Giorgi G, Nuti R. The efficacy and tolerability of glucosamine sulfate in the treatment of knee osteoarthritis: A randomized, double-blind, placebo-controlled trial. Curr Ther Res Clin Exp 2009; 70(3): 185-96. http://dx.doi.org/10.1016/j.curtheres.2009.05.004 PMID: 24683229

[20] Houpt JB, McMillan R, Wein C, Paget-Dellio SD. Effect of glucosamine hydrochloride in the treatment of pain of osteoarthritis of the knee. J Rheumatol 1999; 26(11): 2423-30.

PMID: 10555905

[21] McAlindon T, Formica M, LaValley M, Lehmer M, Kabbara K. Effectiveness of glucosamine for symptoms of knee osteoarthritis: results from an internet-based randomized double-blind controlled trial. Am J Med 2004; 117(9): 643-9.

http://dx.doi.org/10.1016/j.amjmed.2004.06.023 PMID: 15501201

[22] Cibere J, Kopec JA, Thorne A, et al. Randomized, double-blind, placebo-controlled glucosamine discontinuation trial in knee osteoarthritis. Arthritis Rheum 2004; 51(5): 738-45.

http://dx.doi.org/10.1002/art.20697 PMID: 15478160

[23] Clegg DO, Reda DJ, Harris CL, et al. Glucosamine, chondroitin sulfate, and the two in combination for painful knee osteoarthritis. N Engl J Med 2006; 354(8): 795-808.

http://dx.doi.org/10.1056/NEJMoa052771 PMID: 16495392

[24] Frestedt JL, Walsh M, Kuskowski MA, Zenk JL. A natural mineral supplement provides relief from knee osteoarthritis symptoms: a randomized controlled pilot trial. Nutr J 2008; 7: 9.

http://dx.doi.org/10.1186/1475-2891-7-9 PMID: 18279523

[25] Chopra A, Saluja M, Tillu G, et al. A Randomized Controlled Exploratory Evaluation of Standardized Ayurvedic Formulations in Symptomatic Osteoarthritis Knees: A Government of India NMITLI Project. Evid Based Complement Alternat Med 2011; 2011: 724291 .

http://dx.doi.org/10.1155/2011/724291 PMID: 20981160

[26] Grootendorst P, Marshall D, Pericak D, Bellamy N, Feeny D, Torrance GW. A model to estimate health utilities index mark 3 utility scores from WOMAC index scores in patients with osteoarthritis of the knee. J Rheumatol 2007; 34(3): 534-42. PMID: 17343301

[27] Mazzuca SA, Brandt KD, Katz BP, Hanna MP, Melfi CA. Reduced utilization and cost of primary care clinic visits resulting from selfcare education for patients with osteoarthritis of the knee. Arthritis Rheum 1999; 42(6): 1267-73.

http://dx.doi.org/10.1002/1529-0131(199906)42:6<1267::AIDANR25>3.0.CO;2-E PMID: 10366121

[28] Silva GS, Sullivan JK, Katz JN, Messier SP, Hunter DJ, Losina E. Long-term clinical and economic outcomes of a short-term physical activity program in knee osteoarthritis patients. Osteoarthritis Cartilage 2020; 28(6): 735-43.

http://dx.doi.org/10.1016/j.joca.2020.01.017 PMID: 32169730
[29] Losina E, Smith KC, Paltiel AD, et al. Cost-Effectiveness of Diet and Exercise for Overweight and Obese Patients With Knee Osteoarthritis. Arthritis Care Res (Hoboken) 2019; 71(7): 855-64 http://dx.doi.org/10.1002/acr.23716 PMID: 30055077

[30] Katz JN, Smith SR, Collins JE, et al. Cost-effectiveness of nonsteroidal anti-inflammatory drugs and opioids in the treatment of knee osteoarthritis in older patients with multiple comorbidities. Osteoarthritis Cartilage 2016; 24(3): 409-18.

http://dx.doi.org/10.1016/j.joca.2015.10.006 PMID: 26525846

[31] Johnson C, Stephens J, Walker C, Cappelleri JC, Shelbaya A. Economic Outcomes Related to Persistence and Dosing of Celecoxib in Patients with Osteoarthritis (OA) Using a Retrospective Claims Database Analysis. Clinicoecon Outcomes Res 2020; 12: 57-67. http://dx.doi.org/10.2147/CEOR.S199145 PMID: 32021340

[32] Shelbaya A, Solem CT, Walker C, Wan Y, Johnson C, Cappelleri JC. The economic and clinical burden of early versus late initiation of celecoxib among patients with osteoarthritis. Clinicoecon Outcomes Res 2018; 10: 213-22. http://dx.doi.org/10.2147/CEOR.S140208 PMID: 29670383

[33] Losina E, Usiskin IM, Smith SR, et al. Cost-effectiveness of generic celecoxib in knee osteoarthritis for average-risk patients: a model-based evaluation. Osteoarthritis Cartilage 2018; 26(5): 641-50. http://dx.doi.org/10.1016/j.joca.2018.02.898 PMID: 29481917

[34] Mackowiak J, Jones JT, Dasa V. A comparison of 4-year total medical care costs, adverse outcomes, and opioid/prescription analgesic use for 3 knee osteoarthritis pain treatments: Intra-articular hyaluronic acid, intra-articular corticosteroids, and knee arthroplasty. Semin Arthritis Rheum 2020; 50(6): 1525-34. http://dx.doi.org/10.1016/j.semarthrit.2020.01.003 32088013

[35] Rosen J, Niazi F, Dysart S. Cost-Effectiveness of Treating Early to Moderate Stage Knee Osteoarthritis with Intra-articular Hyaluronic Acid Compared to Conservative Interventions. Adv Ther 2020; 37(1): 344-52.

http://dx.doi.org/10.1007/s12325-019-01142-x PMID: 31735982

[36] Salmon JH, Rat AC, Charlot-Lambrecht I, Eschard JP, Jolly D, Fautrel B. Cost Effectiveness of Intra-Articular Hyaluronic Acid and Disease-Modifying Drugs in Knee Osteoarthritis. Pharmacoeconomics 2018; 36(11): 1321-31. http://dx.doi.org/10.1007/s40273-018-0695-5 PMID: 30047014

[37] Kamaruzaman H, Kinghorn P, Oppong R. Cost-effectiveness of surgical interventions for the management of osteoarthritis: a systematic review of the literature. BMC Musculoskelet Disord 2017; 18(1): 183

http://dx.doi.org/10.1186/s12891-017-1540-2 PMID: 28486957

[38] Kadambi A, Leipold RJ, Kansal AR, Sorensen S, Getsios D. Inclusion of compliance and persistence in economic models: past, present and future. Appl Health Econ Health Policy 2012; 10(6): 36579.

http://dx.doi.org/10.1007/BF03261872 PMID: 23030640

[39] Chiatti C, Bustacchini S, Furneri G, et al. The economic burden of inappropriate drug prescribing, lack of adherence and compliance, adverse drug events in older people: a systematic review. Drug Saf 2012; 35(Suppl. 1): 73-87.

http://dx.doi.org/10.1007/BF03319105 PMID: 23446788

[40] Honvo G, Reginster JY, Rabenda V, et al. Safety of Symptomatic Slow-Acting Drugs for Osteoarthritis: Outcomes of a Systematic Review and Meta-Analysis. Drugs Aging 2019; 36(Suppl. 1): 6599.

http://dx.doi.org/10.1007/s40266-019-00662-z PMID: 31073924

[41] Hiligsmann M, Pinto D, Dennison E, et al. Patients' preferences for osteoarthritis treatment: the value of stated-preference studies. Aging Clin Exp Res 2019; 31(1): 1-3.

http://dx.doi.org/10.1007/s40520-018-1098-3 PMID: 30607878

[42] Posnett J, Dixit S, Oppenheimer B, Kili S, Mehin N. Patient preference and willingness to pay for knee osteoarthritis treatments. Patient Prefer Adherence 2015; 9: 733-44.

PMID: 26089650

[43] Gouze JN, Bianchi A, Bécuwe P, et al. Glucosamine modulates IL1-induced activation of rat chondrocytes at a receptor level, and by inhibiting the NF-kappa B pathway. FEBS Lett 2002; 510(3): 16670 .

http://dx.doi.org/10.1016/S0014-5793(01)03255-0

PMID: 11801247 
[44] Largo R, Alvarez-Soria MA, Díez-Ortego I, et al. Glucosamine inhibits IL-1beta-induced NFkappaB activation in human osteoarthritic chondrocytes. Osteoarthritis Cartilage 2003; 11(4): 290-8. http://dx.doi.org/10.1016/S1063-4584(03)00028-1 12681956
[45] Chiusaroli R, Piepoli T, Zanelli T, et al. Experimental pharmacology of glucosamine sulfate. Int J Rheumatol 2011; 2011: 939265. http://dx.doi.org/10.1155/2011/939265 PMID:

DISCLAIMER: The above article has been published in Epub (ahead of print) on the basis of the materials provided by the author. The Editorial Department reserves the right to make minor modifications for further improvement of the manuscript. 